\title{
Liver disease and mortality among patients with hip fracture: does gender matter?
}

This article was published in the following Dove Press journal:

Clinical Epidemiology

\section{Ling-Yue Zhao \\ Yi-Jun Luo \\ Jing Zhu}

Department of Ambulatory Surgery, Shenzhen Nanshan District People's Hospital, Shenzhen, Guangdong

518052, People's Republic of China
Correspondence: Yi-Jun Luo Department of Day Surgery, Shenzhen Nanshan District People's Hospital, 89 Taoyuan Road, Shenzhen, Guangdong 518052, People's Republic of China Tel +86755 5I 3 II I I

Fax +86755 5I3 II 2 I Email nsluoyijun@yeah.net

\section{Dear editor}

Several studies have revealed that the 1-year all-cause mortality rate was about $20 \%$ following hip fracture (HF), which highlights the importance of the prognostic impact of other comorbidities on mortality. ${ }^{1}$

Recently, we read with great interest the study by Montomoli et al. ${ }^{2}$ The authors performed a nationwide cohort study to investigate the prognostic impact of liver disease on 30-day mortality and the 31-365-day mortality among patients with HF. They concluded that relative to patients without liver disease, patients with liver disease, especially those with liver cirrhosis, had higher 30-day mortality and 31-365-day mortality rate following HF. The research appears informative clinically. Thus, there are some issues that that should be addressed regarding this study.

First, we were confused regarding the method for the diagnosis of liver cirrhosis. Because the early phase of liver cirrhosis has no apparent signs and symptoms, diagnosis in some patients can be missed without the detailed inspection. Consequently, the prevalence of liver cirrhosis may be underestimated, which may affect the results.

Second, $\sim 90 \%$ of patients with HF received hip surgery in this study. Much more patients were elderly and classified as high comorbidity level, which was the risk factor for surgical complication and related to the worsened prognosis. ${ }^{3}$ Nevertheless, the surgery-associated complications, such as chest infection, early failure pneumonia, and pulmonary embolism, were not reported in the study by Montomoli et al. ${ }^{2}$ Indeed, this information is critical in analyzing the association between liver disease and mortality in HF patients.

Third, the nonalcoholic fatty liver disease (NAFLD) is the most common liver disorder all over the world. Previous pieces of evidence suggested that the associations between NAFLD and mortality were different between men and women. ${ }^{4}$ NAFLD was associated with higher risk of all-cause mortality and death from cancer and cardiovascular disease in women; but these associations were not detected in men. ${ }^{4}$ This finding was also observed in the study by Montomoli et al, ${ }^{2}$ which showed that association of noncirrhotic liver disease and overall mortality was sex-based (HR: 1.10; 95\% CI: 0.90-1.35 for man and HR: 1.36; $95 \%$ CI: $1.15-1.61$ for women, respectively). The reason for this finding may be due to the levels of sex hormones, which is more closely associated with obesity, metabolic phenotype, and the degree of inflammation. ${ }^{4}$ Thus, further studies are warranted to investigate the mechanisms responsible for sex-based differences in the association between the liver disease and mortality. submit your manuscript Dovepress f $y$ in 


\section{Disclosure}

The authors report no conflicts of interest in this communication.

\section{References}

1. Mundi S, Pindiprolu B, Simunovic N, Bhandari M. Similar mortality rates in hip fracture patients over the past 31 years. Acta Orthop. 2014;85(1):54-59.
2. Montomoli J, Erichsen R, Gammelager H, Pedersen A. Liver disease and mortality among patients with hip fracture: a population-based cohort study. Clin Epidemiol. 2018;10:991-1000.

3. Roche JJ, Wenn RT, Sahota O, Moran CG. Effect of comorbidities and postoperative complications on mortality after hip fracture in elderly people: prospective observational cohort study. $B M J$. 2005;331(7529):1374.

4. Hwang YC, Ahn HY, Park SW, Park CY. Nonalcoholic fatty liver disease associates with increased overall mortality and death from cancer, cardiovascular disease, and liver disease in women but not men. Clin Gastroenterol Hepatol. 2018;16(7):1131-1137.e5. 


\section{Authors' reply \\ Jonathan Montomoli \\ Rune Erichsen \\ Henrik Gammelager \\ Alma B Pedersen}

Department of Clinical Epidemiology, Aarhus University Hospital, Aarhus N, Aarhus, Denmark

Correspondence: Jonathan Montomoli

Department of Clinical Epidemiology, Aarhus University Hospital,

Olof Palmes, Allé 43-45, 8200 Aarhus N, Aarhus, Denmark

Tel +4587167212

Fax +4587167215

Email jonathan.montomoli@gmail.com

\section{Dear editor}

We thank Zhao et al for showing interest in our work. ${ }^{1}$

First, we agreed that misclassification of patients with asymptomatic liver disease may have hampered our results.

Hence, some patients with liver disease are likely to have been categorized in the cohort without liver disease causing us to underestimate the prognostic impact of liver disease on hip fracture (HF).

Second, with respect to complications following HF, we agree that these intermediate steps are clinically relevant to study as the underlying cause for the increased mortality. However, studying complications after HF and subsequent mortality requires detailed mediation analyses and thus falls outside the scope of our study.

Third, and finally, we acknowledge that studying the impact of nonalcoholic fatty liver disease on HF prognosis would be interesting and important. Unfortunately, our data did not provide the opportunity to differentiate nonalcoholic fatty liver disease from other noncirrhotic liver diseases, and we were thus unable to investigate further. The fact that we observed differences in hazards ratios for men and women may be explained by underlying differences in hormone levels as suggested by Zhao et al, but this is purely speculative and not something our data provides basis for.

\section{Disclosure}

The authors report no conflicts of interest in this communication.

\section{Reference}

1. Montomoli J, Erichsen R, Gammelager H, Becic Pedersen A. Liver disease and mortality among patients with hip fracture: a populationbased cohort study. Clin Epidemiol. 2018;10:991-1000.

Dove Medical Press encourages responsible, free and frank academic debate. The content of the Clinical Epidemiology 'letters to the editor' section does not necessarily represent the views of Dove Medical Press, its officers, agents, employees, related entities or the Clinical Epidemiology editors. While all reasonable steps have been taken to confirm the content of each letter, Dove Medical Press accepts no liability in respect of the content of any letter, nor is it responsible for the content and accuracy of any letter to the editor.

Clinical Epidemiology

\section{Publish your work in this journal}

Clinical Epidemiology is an international, peer-reviewed, open access, online journal focusing on disease and drug epidemiology, identification of risk factors and screening procedures to develop optimal preventative initiatives and programs. Specific topics include: diagnosis, prognosis, treatment, screening, prevention, risk factor modification,

\section{Dovepress}

systematic reviews, risk and safety of medical interventions, epidemiology and biostatistical methods, and evaluation of guidelines, translational medicine, health policies and economic evaluations. The manuscript management system is completely online and includes a very quick and fair peer-review system, which is all easy to use. 